\title{
RE-DUÇÃO: DAS CIÊNCIAS DAS RELIGIÕES A UMA INVESTIGAÇÃO FENOMENOLÓGICO-HERMENÊUTICA DO FENÔMENO RELIGIOSO
}

\author{
Reduction: from the sciences of religions to a phenomenological-hermeneutic \\ investigation of the religious phenomenon
}

Marcos Aurélio Fernandes ${ }^{1}$

\begin{abstract}
RESUMO
Este artigo pretende ensaiar um fio condutor para a investigação fenomenológico-hermenêutica da religião. A condução investigativa se propõe como re-dução (retorno às fontes da experiência religiosa). A perspectiva é de um caminho que parte das ciências da religião, especialmente a história e a antropologia das religiões, para uma fenomenologia descritiva, uma fenomenologia essencial e, por fim, uma fenomenologia transcendental do fenômeno religioso. O sagrado é o elemento do fenômeno religioso. É uma região de ser, uma estruturação de sentido, um mundo aberto pelo lógos do fenômeno religioso. Ele abre a dimensão do "nada do mistério". A fenomenologia hermenêutica, investigando-o, faz-se, por fim, hermética.
\end{abstract}

Palavras-chave: religião, sagrado, reduções fenomenológicas, hermenêutica.

\begin{abstract}
This article intends to try a common thread for the phenomenological-hermeneutic investigation of religion. The investigative conduct is proposed as a reduction (return to the sources of religious experience). The perspective is that of a path that starts from the sciences of religion, especially the history and anthropology of religions, towards a descriptive phenomenology, an essential phenomenology, and, finally, a transcendental phenomenology of the religious phenomenon. The sacred is the element of the religious phenomenon. It is a region of being, a structure of meaning, a world opened by the logos of the religious phenomenon. It opens the dimension of the "nothingness of mystery". Hermeneutical phenomenology, investigating it, becomes, in the end, hermetic.
\end{abstract}

Palavras-chave: religião, sagrado, reduções fenomenológicas, hermenêutica.

A Max Scheler, em homenagem pelos 100 anos de "O eterno no homem”.

\section{Introdução}

A religião e, respectivamente, o “homo religiosus” aparece como um “factum” histórico.

A história da religião tem produzido um imenso material, um imenso acervo de informações,

Doutor em Filosofia pela Pontificia Università Antonianum, de Roma. Professor Adjunto da Universidade de Brasília (UnB), no Departamento de Filosofia. Membro do Programa de Pós-Graduação em Filosofia (PPGFIL). E-mail: framarcosaurelio@hotmail.com . 
de interpretações, de reflexões, sobre as religiões em suas mais variadas concreções. O acesso do conhecimento objetivo ao factual da religião, hoje, parece mais amplo do que nunca. $\mathrm{O}$ problema, porém, começa justamente aí. O que os fatos revelam?

O fenômeno religioso é um fenômeno histórico. Quando entramos em contato com ele é como se acessássemos um caos de formas numa multiplicidade imensa de contextos e tradições. E, além disso, tudo está em constante devir, participando do devir e do acontecer do próprio humano. O estudioso que investiga este "factum" se interessa, então, pelas fontes que possibilitam o seu conhecimento objetivo: textos, monumentos, inscrições, tradições orais, costumes, provenientes dos meios mais diversos. Aqui reina a heterogeneidade e, ao mesmo tempo, a mistura dos “materiais".

A lida com este fenômeno em sua factualidade requer, então, o que podemos chamar de uma "fenomenologia descritiva”. Esta, por sua vez, requer uma "fenomenologia essencial”, que é também uma "fenomenologia transcendental”.

Por "fenomenologia descritiva" entende-se, aqui, a mera descrição do fenômeno, em seu caráter factual, tal como ele significativamente se doa ao homem, sem se pronunciar sobre a essência e/ou sentido de ser. Já a “fenomenologia essencial” parte do pressuposto de que o fenômeno se dá a conhecer ao homem em sua essência, constituição e sentido de ser. Chamamos de "fenomenologia essencial” a exposição desta essência e sentido de ser, com outras palavras, a elucidação da estrutura possibilitadora, perfilhadora e configuradora do fenômeno, exposição que deve se pautar pelo que se mostra do fenômeno a um olhar ontológico, dentro dos limites em que se mostra, sem, contudo, recorrer a construções conceituais e especulações forçadas de fora. Antes, o que deve forçar a exposição é o fenômeno mesmo em sua constituição e sentido de ser. Chamamos de "fenomenologia transcendental" aquela que opera as reduções fenomenológica, eidética e transcendental no relacionamento com o fenômeno em questão. Ela expõe como o fenômeno se constitui na dinâmica da intencionalidade. Exercita um retorno ao solo primigênio de toda a constituição de sentido de ser: a consciência no sentido do eu absoluto projetante de mundo e precedente ao mundo, em Husserl (1968); o “Dasein”, isto é, a abertura de ser para o ser de tudo o que, de alguma maneira é, em Heidegger (2012). Ao “Dasein” pertence, como constituição fundamental, o ser-no-mundo - ele é abertura de mundo e o mundo lhe pertence de modo transcendental. Para nós, a fenomenologia da consciência é apenas uma etapa prévia de elucidação dos fenômenos. Nós procuramos seguir o caminho da fenomenologia 
no sentido da ontologia fundamental de Heidegger (ontologia como questão do ser, onde "ser" significa a diferença ontológica). Fenomenologia é, neste ponto, método da investigação ontológica. O sentido metodológico da descrição fenomenológica (transcendental, isto é, ontológica) é, porém, interpretação. O “lógos” da fenomenologia é, assim, hermenêutico: expõe, anuncia, sentidos de ser, constituições de ser, estruturas fundamentais de ser. "Hermenêutica” não é, aqui, neste caminho de pensamento aberto por Heidegger, arte ou técnica de interpretação de textos, nem teoria e método de tradução de uma comunidade linguística para outra, ou seja, a leitura do sentido de uma estrutura significante em sua intenção significativa dentro de uma comunidade linguística. "Hermenêutica” é, aqui, a linguagem do mistério da existência, melhor, é o acontecer da linguagem do mistério na estrutura da língua. O cerne da hermenêutica é, assim, o hermético (o velado do mistério). Hermeneuta é aquele que capta a verdade de ser e tempo: aquele que no patente vê o latente e, no presente, vê a vigência do ausente (do passado e do futuro).

Neste artigo, pretendemos traçar este movimento de pensamento, que um encaminhamento de uma re-dução, isto é, de um retorno (re-) às fontes da experiência religiosa, o qual segue um determinado “ductus”, isto é, um determinado fio condutor, dado pelo fenômeno e seu sentido de ser (re-dução como "reductio": recondução à origem, retorno ao originário).

\section{De uma fenomenologia descritiva do fenômeno religioso em sua doação histórica, exercida no horizonte da história das religiões.}

O caráter investigador reflexivo em torno da religião requer que se traga à tona os fatos das religiões e se interprete o que eles revelam em seus sentidos. Neste quesito, a investigação histórica das religiões presta um préstimo fundamental. Ela trata do devir das formas de fenômeno religioso em seus contextos, a partir da pesquisa crítica de fontes, isto é, de textos, monumentos, inscrições, tradições orais, costumes, etc., provenientes de meios geográficos, sócio-culturais, os mais diversos. Aqui aparece uma grande heterogeneidade e, ao mesmo tempo, uma grande mistura. Tem-se acesso a uma variante infinita (sempre ainda indefinida, inesgotável) de experiências religiosas fundamentais. 
Para a fenomenologia da religião, porém, a apropriação deste material requer uma atenção toda própria. A compreensão fenomenológica requer fazer a experiência de uma tomada dos fenômenos, tornados objetos na investigação científica positiva, em sua originariedade. Uma investigação fenomenológica da consciência religiosa (ou da vivência ou da experiência de vida religiosa) não pode ter o caráter de uma mera exposição historiográfica, nem de uma construção teórico guiada pela necessidade de um "sistema” (filosofia da religião construtiva). É preciso, como fenomenologia essencial e como fenomenologia transcendental, realizar um movimento de re-dução, isto é, de recondução. Dito mais claramente, em jogo está uma

recondução dos fenômenos esclarecidos de maneira autêntica e visualizados como genuinamente originários da consciência pura e da sua constituição. Mas é ali que se encontra a problemática: alcançar e compreender tais fenômenos em geral a partir do histórico e, a este em sua faticidade, em sua compreensão fenomenológico originária (HEIDEGGER, 2010, p. 289).

A investigação positiva e objetiva da historiografia, vale dizer, da historiologia, opera com certo modo de apropriação e de compreensão dos fenômenos históricos que precisa ser tematizado e que não pode ser tematizado historiograficamente. Na investigação historiográfica a tematização da história em sua historicidade se dá através de um processo de objetivação, que opera através do pensamento representacional e calculador (em sentido amplo, de cômputo historiográfico). Aqui está em jogo o empenho de tornar objetiva a história. Para esta forma de investigação, porém, só é objetivo o que se deixa comparar. Através da comparação se busca alcançar a explicação. O alcance das pesquisas só vai até onde vai a comparação e a explicação. Mas, o que é do único, do incomparável? O que é do simples? O que é do original? Só pode aparecer, aqui, como exceção. Toda explicação recorre ao já existente, remete ao já sabido, excluindo tudo o que é libertador e criativo, tudo que é inaugural, de sua originariedade própria (LEÃO, 2010). Ora, nisso, a compreensão fenomenológica deve se diferenciar da compreensão historiográfica. Ela deve deixar-ser o único, o incomparável, o extraordinário, o simples, o original, em sua originariedade. Na explicação, todo o extraordinário se reduz ao ordinário e, assim, se perde em seu caráter próprio. Para, para uma fenomenologia da religião, os empreendimentos de história comparada das religiões, iniciados no século XIX por Max Müller (2010), a partir de seus estudos linguísticos e mitológicos, por mais exitosos que possam ser, permanecem insuficientes. 
A história das religiões explica os fenômenos religiosos a partir dos seus mundos religiosos circundantes, na diversidade das épocas. Ela opera, porém, com toda uma interpretação das fontes. Os motivos e as tendências desta interpretação nem sempre, ou quiçá até na maior parte das vezes, permanecem encobertos para os próprios investigadores. Por isso, Heidegger advertia que "toda objetividade histórico-científica e a compreensão históricoobjetiva não garantem nada enquanto tudo não for esclarecido no que diz respeito ao preconceito condutor [leitenden Vorgriff]” (2010, p. 70).

Aqui estamos diante de uma tarefa interpretativo-hermenêutica. Toda interpretação se funda numa posição prévia (Vorhabe). Trata-se de um modo de se ter (haben) algo perto de si, de se ater a algo, de tê-lo presente, de se propô-lo numa operação, numa ação, na constituição de algo. Na interpretação, é essa posição prévia, este modo de se ater ao que é atinente, à coisa em questão, que possibilita o horizonte das articulações de significações e sentidos. Depois, na interpretação, o desvelamento do que está em questão, do a ser interpretado (interpretandum), se realiza numa visão prévia (Vorsicht), isto é, se cumpre numa perspectiva em que se encara e se vê o conjunto das articulações de significações e sentidos. Essa visão "fixa o parâmetro na perspectiva do qual o compreendido há de ser interpretado” (HEIDEGGER, 2012, p. 211). Toda vidência é, na interpretação, dada numa e a partir de uma pre-vidência. Em terceiro lugar, a interpretação traz o que lhe é atinente e aquilo que ela encara a uma apreensão que já pressupõe, a cada vez, uma antecipação na forma de uma concepção prévia (Vorgriff). A apreensão prévia não é a apreensão do a ser interpretado, mas a apreensão, justamente, das posições prévias e das visões prévias. Aqui se decide como se realiza a formação do conceito (Begriffsbildung). A formação de conceito é um momento integrante da interpretação e uma das questões fundamentais para a hermenêutica (GADAMER, 1997). Essa formação conceitual pode haurir os conceitos a partir do ente em questão e de seu modo de ser ou pode forçar um aparato conceitual estranho, e, então, o ente em questão, em vez de se deixar desvendar, resiste e se encobre. Neste caso, a interpretação, em vez de desvendar, veda o acesso ao que está em questão. Ora, a posição prévia, a visão prévia e a concepção prévia podem não se fazer originárias, isto é, podem não deixar emergir os fenômenos em sua originariedade, ou seja, como eles mesmos, em seus próprios modos de ser, tais como eles se dão na imediatez da vivência da consciência religiosa, ou melhor, da experiência fática da vida.

É necessário mostrar também que todos os motivos da compreensão histórica devem ser sempre despertados pela experiência fática da vida. A ciência da 
história somente tem a tarefa de aplicá-la mediante o método rigoroso e formal. Do presente vivo vão surgindo as tendências de compreensão que logo se configurarão num método "exato”. A “exatidão do método” não é garantia suficiente de compreensão correta. O aparato científico-metódico - a crítica das fontes conforme o método filológico exato - pode permanecer completamente intocado, se com todo o preconceito condutor não acertar com a própria objetualidade. Apesar disso, a moderna história das religiões muito terá feito pela fenomenologia se se submeter a uma destruição [Destruktion] fenomenológica. Somente então a fenomenologia poderá levar em conta a história das religiões (HEIDEGGER, 2010, p. 70).

Destruição não quer dizer, aqui, na fenomenologia, aniquilação. Diz o contrário: resgate. Diz desentulhar os fenômenos, removendo conceituações, perspectivas, modos de se ter e de se propô-los, que são estranhos a eles mesmos, isto é, aos seus modos de se constituírem, aos seus modos de ser, de se deixar apreender e conceber. Destruir é, dito negativamente, corrigir o modo de se ater à coisa em questão, ao fenômeno, a perspectiva pela qual se o encara, a formação do conceito. Dito, porém, positivamente, é abrir caminho para o originário do fenômeno tal como ele emerge na experiência fática da vida. Destruição diz, pois, re-dução: um movimento de retorno (re-) à fontes da experiência dos fenômenos (à vida!). A destruição é crítica: ela procura discernir e captar o desafinado a partir da afinação, o desfigurado a partir da forma enquanto doação de ser no pique de suas possibilidades. Ela, neste sentido, desenrijece o real e des-petrifica o fluxo da realidade e o deixa emergir em sua própria dinâmica de realização.

A história das religiões oferece à fenomenologia da religião um imenso acervo de materiais a serem interpretados. Também a psicologia e a sociologia da religião, com seus estudos analíticos, a partir de perspectivas diversas, tratam do fato religioso. O fenômeno religioso aparece, aqui, como momento da realidade anímica, psíquica, humana; ou como momento da realidade social humana. Terá certa função no sistema psíquico ou no sistema social. De acordo com os pontos de partida e as tendências das diversas "abordagens" esta função será interpretada de modo diverso. As significações dos fenômenos serão lidas em universos de linguagem diversos. Contudo, para a "fenomenologia descritiva" da religião, tudo isso pode ser útil, mas não basta. Carece de se apreender o fenômeno religioso em sua modalidade própria de aparecimento, isto é, na perspectiva e no horizonte de sentido próprios do sagrado.

Não basta encarar o sagrado de modo positivo e positivista como manifestação da atividade humana. Não basta descrever e explicar a religião como um complexo de mitos, 
crenças e ritos, excluindo o sobrenatural, o mistério, a divindade. Não basta encarar o sagrado como produto de uma consciência coletiva, que faz viver para os indivíduos o ideal comunitário-social (DURKHEIM, 2013). Também não basta conceber a neurose obsessiva como a contrapartida patológica da formação das religiões, encarando a neurose obsessiva como religiosidade individual e a religião como neurose obsessiva da humanidade. Não basta, ainda desmascarar a religião como algo análogo a uma um sistema de crenças ilusórias, isto é, como uma ilusão que se enraíza nos desejos inconscientes do homem, e indicar a função primordial da religião no consolo diante da dureza da vida (FREUD, 1961). Não basta nem mesmo, do lado oposto, descobrir, encontrar e interpretar a religião no horizonte do inconsciente coletivo e dos arquétipos e tomar o sagrado como algo que é dado como separado do profano e dado em sua significação mais que em relação à consciência e ao eu, ao inconsciente, mais que ao inconsciente individual, ao inconsciente coletivo, como uma imagem do Si-mesmo, com a função de liberar forças psíquicas contrapostas à consciência e de constituir um recipiente de transformações do todo da psique, no processo de individuação (JUNG, 2015).

Toda ciência é, de alguma maneira, explicativa. Isto quer dizer: toda ciência opera uma determinada hermenêutica, na medida em que o desconhecido é, sempre de novo, reconduzido ao conhecido, e o incompreensível ao compreensível. Quando falamos de "explicar alguma coisa”, usualmente, nós tomamos esta expressão neste sentido: de uma recondução do que é desconhecido ao que é conhecido, do que é incompreensível ao que é compreensível. Já a descrição de fatos é dada na ótica de uma determinada explicação dos mesmos. O típico da investigação científica, com efeito, é a precisão adotada justamente na preparação das condições da própria explicação. Por sua vez, toda explicação já é um ato de interpretação. mesmo quando apenas observamos e descrevemos fatos já estamos interpretando. É que não existem fatos que já não sejam dados no horizonte de uma determinada compreensão, ainda que esta compreensão precise ser, cada vez mais, melhorada e, por isto, revisada segundo as suas condições de explicação.

Para uma fenomenologia essencial do fenômeno religioso: a busca de seu elemento e de seu a priori.

Não basta, pois, descrever e interpretar o fenômeno religioso e a religião desde âmbitos e perspectivas extra-religiosas (psicológicas, sociológicas, etc.). Uma fenomenologia descritiva 
da religião requer que se os apreenda em sua modalidade própria, em seu próprio elemento, como uma religação com o sagrado (RIES, 1989). Rudolf Otto (2005), em “O Sagrado”, aparecido em 1917, encontra no "numinosum” a manifestação de um valor divino que constitui o elemento fundamental e o princípio vivente de todas as religiões. Falando de "numinosum”, pretende-se dar a entender o caráter do totalmente outro, que se mostra como um mysterium tremendum, que inspira veneração e temor, e como um fascinosum, isto é, algo desconhecido que fascina a consciência enquanto consciência religiosa. O numinoso, neste sentido, pode ser experimentado tanto a partir de uma coisa visível quanto a partir de uma presença invisível. A consciência do numinoso se dá na experiência do sagrado. A propósito, em “O eterno no homem", publicado em 1921, no estudo intitulado “fenomenologia essencial da religião”, lemos uma apreciação positiva, embora com senões, feita por Max Scheler desta contribuição dada por Rudolf Otto:

Recentemente um escritor muito benemérito da filosofia da religião explicou a qualidade do sagrado com notável fineza e profundidade. Rudolf Otto distingue no seu livro $O$ sagrado uma pluralidade de momentos: frente aos atributos do divino por ele qualificado como "racionais" está o excedente "irracional". Otto dá a estes momentos particulares nomes latinos, para distinguir-lhes já na denominação de valores análogos, mas extra-religiosos. Assim ele conduz ao "mysterium tremendum", ao momento da "majestas", a aquele do "energético", o momento do "misterioso", do "fascinosum" (que como atraente, fascinante, se opõe ao momento do tremendum), o momento que exprime proteção e expiação. Tanto pouco posso seguir assim a teoria do conhecimento religioso de Otto, desenvolvida nas últimas sessões do seu livro, com tanta simpatia saúdo, ao invés, na sessão descritiva do seu livro a primeira tentativa de apresentar com o método da discussão fenomenológica as mais importantes qualidades do sagrado, como distinta modalidade de valor - que é objeto determinado de toda e cada religião. Muito justamente e de todo no sentido do método fenomenológico diz Otto a respeito da sua investigação: "porque a categoria do sagrado é perfeitamente sui generis, essa, como todo dado primário e elementar não é definível em sentido estreito, mas somente descritível. Pode-se só ajudar o ouvinte a compreender, procurando conduzilo através da discussão a aquele nível do próprio sentimento, onde a categoria do sagrado deve então surgir, mover-se, se tornar consciente" (SCHELER, 1991, p. 187).

Para Scheler, as descrições de Otto do fenomenológico religioso à luz do seu elemento próprio, o sagrado, e as elucidações do sagrado a partir do "numinosum” e de seus elementos, o "tremendum" e o "fascinans", o esclarecimento do "sanctum” enquanto valor numinoso, a remissão ao mistério como o "totalmente outro", abriram um caminho para o propósito de uma investigação e compreensão fenomenológica da religião e das religiões. Essas inquirições deixam aparecer o sagrado em suas qualidades distintas, deixa vir à fala o sagrado como 
categoria sui generis, como dado primitivo e elementar, e, por isso mesmo, indefinível, mas descritível. O sagrado, não se deixa reduzir ao moral e ao racional. Estando mais além disso, enquanto o “misterioso", interpela o humano de duplo modo, pro-voca temor, terror ou horror, por um lado, mas também, por outro lado, fascínio, maravilhamento e admiração e veneração.

Scheler, porém, na citação acima, diz não poder seguir Otto na sua teoria do conhecimento religioso. O problema, para Scheler está na concepção de “a priori” de Otto. Este imposta, de fato, sua teoria do conhecimento religioso, apresentando o sagrado como categoria a priori. Parte, portanto, do horizonte da filosofia transcendental. Na filosofia transcendental dos valores (Windelband, Troeltsch) emerge o tema do a priori religioso.

Windelband escreve sobre "O sagrado" (1915). Heidegger diz que "Windelband (O Sagrado) mostra um olhar penetrante quase na mesma plenitude de fenômenos religiosos, embora numa formulação um tanto racional” (2010, p, 317). Em que consiste esta formulação “um tanto racional”? Heidegger resume esta formulação com as seguintes indicações:

O Sagrado só pode ser determinado pelo compêndio de normas lógicas, éticas e estéticas. São santas enquanto conteúdo de valores de uma realidade racional superior. "O sagrado é, portanto, a consciência da norma do verdadeiro, do bom e do belo, vivenciado como realidade transcendente". "Religião é vida transcendente" (2010, p. 300).

Troeltsch (1915) segue, até certo ponto, na esteira de Windelband. Ele tinha como meta elaborar uma definição essencial e cientificamente válida de religião. Sua filosofia da religião parte de uma descrição dos fenômenos religiosos dados em sua positividade e imediatez. Ele distingue fenômenos religiosos principais e periféricos. Heidegger diz que, para Troeltsch, “o fenômeno principal é a fé em poder obter a presença de Deus, com o que está também conjuntamente dado, em princípio, o imperativo ético” (2010, p. 24). As formas periféricas são as condições sociais, ético-econômicas, etc., pelas quais as religiões assumem uma configuração fática no mundo histórico. A possibilidade de uma descrição, ele dessumia do trabalho feito pela psicologia descritiva de William James (2017) e de Dilthey (2008). À descrição, fundamentalmente psicológica, se seguia, como segunda tarefa, a teoria do conhecimento da religião e do momento de validez do conteúdo nos processos psíquicos. A teoria do conhecimento tinha como tarefa investigar as leis racionais da formação das ideias religiosas. Em jogo estariam determinadas leis apriorísticas subjacentes aos fenômenos religiosos. Apoiando-se na teoria do conhecimento de Windelband e de Rickert, Troetsch, segundo Heidegger, entendia que:

R E V I S T A R E L E G E N S T H R É S K E I A - 2021 - U F P R 
Existe um a priori sintético do religioso como existe um a priori lógico, ético e religioso. Mostrar este a priori religioso supõe fixar a "verdade" religiosa em geral, o elemento racional do religioso. Troetsch refere-se (sobretudo mais tarde) ao racional, não em sentido do teórico-racionalista, já que racional diz respeito somente à validez geral ou ao racionalmente necessário. Anteriormente, Troeltsch o tinha definido como a priori racional, mais tarde abandonou esta concepção e afirma, sem aportar dados sobre seu conteúdo, que não é racional, mas um a priori irracional, e que, o que importa, é vincular o a priori ético, lógico e estético com o religioso e ver como estes se veem fortalecidos pelo a priori religioso. O trabalho da teoria do conhecimento da religião é crítico: quer separar o fático-psicológico do válido a prior (HEIDEGGER, 2010, p. 25).

Num primeiro momento de seu trabalho, Troeltsch entende o momento "racional” da religião como o que está referido a conteúdos de verdade, num segundo momento, como um ser que está conforme a norma. “A reunificação do a priori assim chamado e ressaltado com as formas psíquicas de aparecer da religião é tarefa da metafísica religiosa” (HEIDEGGER, 2010, p. 27). Esta metafísica é diversa, porém, da metafísica filosófica, “assim como o a priori religioso é algo distinto do a priori teórico” (HEIDEGGER, 2010, p. 27).

Otto também elabora uma teoria do conhecimento da religião no horizonte de uma filosofia transcendental. Seguindo na esteira da interpretação de Kant feita por Fries (OTTO, 1909), ele admite o caráter de experiência psíquica dos fenômenos experimentados pela consciência religiosa, mas procura também remontar do que é fático ao que é válido como valor a priori. A categoria a priori do sagrado é composta tanto de "sentimentos racionais" quanto de "elementos irracionais”. “Considerada em cada uma destas duas partes, ela é uma categoria puramente a priori” (OTTO, 2005, p. 149). As ideias concernentes ao absoluto, a Deus, ao seu ser a partir de si (ens a se) e a seu dar-se como ente necessário, a seus predicados (atributos), ao seu ser "summum bonum”, etc., enfim, estes elementos da metafísica teísta, são de caráter racional. Estes elementos racionais, porém, se compõem com elementos irracionais: “os elementos irracionais da nossa categoria do sagrado conduzem-nos a algo de mais profundo ainda do que a 'razão pura' tomada no sentido habitual, ao que o misticismo chamou, com razão, ‘o fundo da alma’” (OTTO, 2005, p. 150). As ideias do numinoso e os sentimentos que lhe correspondem transcendem a experiência (melhor, a percepção sensível). O que está em jogo são, pois, “conceitos puros” e "sentimentos puros” (não empíricos). Vale a tese de Kant: se "todo o conhecimento se inicia com a experiência, isso não prova que todo ele derive da experiência” (Apud OTTO, 2005, p. 150). 
Max Scheler recusa tal tipo de teoria do conhecimento religioso. Recusa a tese de que o espírito humano possua algo como ideias inatas ou como ideias congênitas. Recusa que a ideia de Deus seja inata. "Somente não existindo uma ideia inata de Deus existe por princípio um crescimento ilimitado do conhecimento natural de Deus nos sempre novos atos de aquisição da história do espírito humano” (SCHELER, 1991, p. 214). Ele recusa também a concepção kantiana de a priori, a saber, a partir de “formas e leis funcionais originárias sintéticas do espírito humano ('categorias’ no sentido de Kant) através de que são cunhadas sobre uma 'matéria’ dada sem ordem (segundo Kant ‘percepções’ e impulsos instintivos) as determinações objetivas formais do ser” (SCHELER, 1991, p. 214-215). Para Scheler, o que está em jogo aqui não são funções de síntese normativas e unidades de forma que in-formam o material sensível (percepções e impulsos instintivos). Unidades de forma, como as “categorias”, são, para Scheler, “dados objetivos”, têm o caráter de datidade (cf. também a noção de “intuição categorial” em Husserl) (HUSSERL, 1993a). O que está em jogo, no domínio do a priori, não é a força formadora, construtiva, produtiva, criadora até, do espírito humano. A intuição do $a$ priori abre toda uma esfera objetiva e essencial. As essencialidades são intuíveis. O a priori formal é, para Scheler, apenas uma parte do reino do a priori. Há também a priori material. Contudo, “o saber do a priori não é de modo algum, portanto, um saber apriorístico”, diz ele (SCHELER, 1991, p. 216). Trata-se, pois, de um saber a posteriori do a priori (formal ou material). Não se trata, porém, de indução, de um saber obtido por generalização, nem de mera formalização. Trata-se de um saber alcançado a partir de ideação (intuição categorial enquanto apreensão da essência). Em jogo está, pois, a capacidade de exercer a intuição do essencial no casual. Por ser assim é que o conhecimento do essencial está aberto a um crescimento e passível de decrescimento na história do espírito humano.

Para Scheler, falar de “sagrado” é falar de uma ideia de valor. Os tipos de valores trazem o caráter de a priori material (não de a priori formal). Sua tese é a de que os tipos de valores fundamentais permanecem sempre os mesmos para o ser humano, independente das suas condições sócio-históricas. Historicamente, varia aquilo que é compreendido sob o domínio desses tipos de valores, mas esses tipos mesmos são invariáveis. Aristóteles (1998) pôs em relevo três tipos de valores: o agradável, o útil e o bom/belo (kalón, o que os medievais chamavam de "bonum honestum"). O útil é um bem, enquanto meio para um fim. O que é bom no sentido moral, porém, é bom enquanto fim em si mesmo (algo que se deseja por si). Scheler (1944) amplia essa ordem dos tipos de bens ou valores para cinco: (1) o agradável, que 
compreende os valores do cômodo; (2) o útil, que compreende os valores da civilização; (3) o nobre, que compreende os valores vitais; (4) o espiritual, que compreende os valores culturais; e (5) o sagrado ou a santidade, que compreende os valores religiosos. Essa ordem comporta uma hierarquia, sendo que a santidade se encontra no topo da escala. Conjugados com esses tipos de valores, de forma correlata, se encontram os tipos de pessoa humana que atuam como modelos. Ao agradável corresponde o tipo que Scheler denomina de "artista na arte de gozar a vida”; ao útil, o tipo que ele chama de "pioneiro da civilização”; ao nobre, corresponde o herói; aos valores do espírito, isto é, da cultura, o gênio; e, por fim, aos valores religiosos, o homo religiosus ou santo.

Como, porém, encarar a questão da conexão entre valores, dados como a priori (formal, segundo a filosofia transcendental dos valores dos neokantianos da escola de Baden, e material, segundo Scheler) e a história, respectivamente, o histórico?

Heidegger (2010, p. 38-43), em suas notas para a preleção intitulada “Introdução à fenomenologia da religião”, curso ministrado em Freiburg no semestre de inverno 1920/1921, notava que a filosofia daquele tempo tomava posição em face ao histórico de três formas: a) pela via platônica; b) pela via historicista; 3) pela via do compromisso entre os extremos - a) e b).

Para a via platônica, o histórico é algo ao qual se deve dar as costas. Postula-se uma esfera supratemporal de substâncias, valores, normas e princípios racionais, que determinam o conhecimento, forjando um conceito de verdade como validez. O problema do platonismo está sempre no desafio de dizer como se dá a conexão entre a esfera ideal de normas e valores com a realidade histórica. O historicismo, do lado oposto, leva a se entregar radicalmente ao histórico. Heidegger nomeia Simmel e Spengler como pensadores deste naipe. Recusa-se toda esfera supratemporal como determinante da história. O homem não é só produto da natureza e da história. Ele é também, em sua subjetividade, produtor da natureza e da história. “A personalidade humana livre possui a história em suas mãos; a história é um produto da livre subjetividade formadora” (HEIDEGGER, 2010, p. 40). Fazendo com que o presente seja visto historicamente se procura uma asseguramento. Com isso, porém, a história perde seu caráter peculiar, a saber, o caráter de inquietação. Isto também acontece, segundo Heidegger, na terceira tendência, a do compromisso entre os extremos. A luta entre dogmatismo e ceticismo, entre absolutismo e relativismo revive aqui. Uma tentativa de equilíbrio, de acordo, de 
compensação ou compromisso é tentada por uma terceira via. "A história é uma realização [Verwirklung] contínua de valores, que, não obstante, nunca se realizam plenamente” (HEIDEGGER, 2010, p. 42). A força dos valores se dão no próprio histórico, de modo, por assim dizer, imanente. O homem configura o próprio futuro contemplando o acervo universal do passado.

É digno de nota que, como Heidegger também indica, nas três vias há uma significativa tendência à tipificação. Em cada uma, porém, a tipificação tem um sentido diferente e uma importância diversa. Na primeira via, a tipificação permite referir o histórico ao mundo absolutamente válido das ideias, transformadas em valores e normas. Na filosofia transcendental dos valores isso aparece na noção de um trabalho “ideográfico” (Windelband). O trabalhar com “tipos ideais” (Max Weber) também segue esta tendência. Para a segunda via (Spengler sobretudo) a tipificação tem uma importância ainda maior. "Como a história é a realidade última, o que importa é seguir as diferentes configurações de conformação” (HEIDEGGER, 2010, p. 43). O conhecimento historiográfico não pode ser produzido através do mero acúmulo de informações concernentes a singularidades, a particularidades, a factualidades. Ele carece, no plano da formação de conceitos, de tipificações morfológicas. "Na terceira via, o que importa é delimitar nitidamente o presente em seu tipo frente ao passado, a fim de determinar o futuro com a ajuda de uma orientação histórico-universal (que só é possível mediante a formação da tipificação histórica)” (HEIDEGGER, 2010, p. 43).

Na história das religiões, baseada na concepção antropológica do "homo religiosus" seja qual for a tendência seguida em relação ao problema valores-história, é notório o trabalho com a tipificação morfológica.

Mircea Eliade (1949), retomando e desenvolvendo descobertas de Nathan Söderblom (2011), Rudolf Otto (2005), Gerardus van der Leeuw (1933) e outros, teve o mérito de fazer um trabalho fenomenológico fundamental, fazendo e deixando ver o fenômeno religioso em sua modalidade própria de experiência e em seu elemento próprio, o sagrado. Ele mostrou o fenômeno religioso como hierofania (manifestação do sagrado). “O sagrado não é um momento da história do conhecimento mas um elemento estrutural da consciência mesma”, assim resume Ries (1989, p. 20) a posição de Eliade. A irrupção do sagrado na experiência humana atesta uma realidade absoluta, transcendente, que abre uma dimensão inteiramente nova de fenômenos e de sentidos destes fenômenos. O homem religioso (homo religiosus) é aquele que vive nesta 
dimensão e que a descobre. A mensagem do sagrado se oferece numa linguagem multivalente, cifrada. Por isso, o “homo religiosus” é, fundamentalmente, um “homo symbolicus”.

Julien Ries (1989) e toda uma escola de pesquisadores desenvolverá, com base neste ponto de partida de Eliade, uma forma de “antropologia religiosa”, distinta da etnologia e da sociologia das religiões, e diversa da antropologia filosófica e daquela imanente às próprias religiões, e que entende o "homo religiosus" como "criador e fruidor do conjunto simbólico do sagrado e enquanto portador de crenças religiosas que guiam sua vida e o seu comportamento" (1989, p. 24).

A linguagem das religiões etnológicas, por exemplo, é marcada pelo mito. No coração do mito vige uma história verdadeira, sagrada e exemplar. Há mitos cosmogônicos, mitos de origem, mitos de renovação, mitos escatológicos etc. Tudo isso impõe o constante desafio de uma interpretação que decifre a carta cifrada do mundo mítico-religioso. A interpretação, porém, em vez de realizar uma decifração unívoca, como um prisma e um espelho, decompõe e reflete a imensa gama de mensagens, de sentidos, mostrando múltiplas possibilidades de articulação e de coerência significativas. O mito é a linguagem simbólica do sagrado. Não se trata de demitizar o mito. A mensagem do mito não se dá no nível da doutrina. A mensagem do mito encontra-se no nível mais fundamental dos comportamentos, das práticas, das experiências fundamentais, nasce de um contato vivo com as fontes da vida. Interpretar, assim, não é decifrar univocamente a mensagem. Interpretar é tornar-se contemporâneo do evento narrado miticamente, que sempre tem o caráter de algo inaugural. Interpretar é tornar-se contemporâneo da origem, a qual não é algo que ficou para trás, como um começo imanente, mas um princípio transcendente que está sempre originando e não deixa de originar nunca. É por isso que as imagens que aí emergem são imagens arquetípicas, não são representações no sentido de afigurações derivadas do real já dado. Investigar a religião é, assim, fazer uma arqueologia do “homo religiosus”, escutando a mensagem do sagrado através de seus símbolos e mitos. Este estudo histórico, porém, para conduzir a um resultado objetivo, precisa de morfologias e tipologias. A “história das crenças e das ideias religiosas” não se produz sem tal empenho de tipificação morfológica.

Uma fenomenologia da religião requer a capacidade de compreender originariamente as vivências religiosas, isto é, compreendê-las, a elas mesmas, nelas mesmas, a partir de seu elemento (medium) próprio, o sagrado. Requer também, ao mesmo tempo e de modo igualmente 
primordial, acessar suas formas de expressão (HEIDEGGER, 2010). “Acima de tudo, compreensibilidade não significa 'racionalização', desmembrar uma vivência em seus ‘componentes lógicos’”. Em jogo está a capacidade de adentrar nos diversos mundos de vivência e de dar atenção e de escutar as diversas formas de expressão. Para Heidegger, é preciso voltar-se à vida religiosa ela mesma, e perguntar: 'quais são as camadas de fundo, as formas de mobilidades que surgem aí? Como constitui essa vida?” (HEIDEGGER, 2010, p. 291). A vida religiosa, aqui, é tomada, melhor, recebida, "de modo puro e livre de prejulgamentos” - mas certamente não sem vigência da tríplice estrutura da interpretação (posição prévia, visão prévia e conceituação prévia) - e interrogada a respeito de suas “mobilidades fundamentais e sua gênese motivacional” (HEIDEGGER, 2010, p. 292). O modo de encarar esta mobilidade não segue, certamente, pela via negativa platônica, nem pela via do historicismo, nem mesmo pela via do compromisso. Ela não visa aquietar a inquietação do histórico, seja pela negação, seja pela entrega inconsequente, seja pelo compromisso. Pelo contrário, a investigação da vida religiosa e de seu caráter de temporalidade e historicidade, com sua inquietude peculiar (lembremo-nos do “cor inquietum”, das Confissões de Agostinho!) torna-se tema especial de indagação.

Um dos elementos de sentido mais significativos, fundantes, na vivência religiosa é a historicidade. Na vivência já se encontra uma doação de sentido especificamente religiosa. Em sua originariedade - não em sua absoluteza [Abgelostheit] teoreticamente teológica -, o mundo da vivência religiosa centra-se numa configuração histórica única (plenitude de vida pessoalmente atuante). Ligado a isso e dele dependendo, o caráter constitutivo do conceito de revelação e de tradição na essência da religião (HEIDEGGER, 2010, p. 307).

Há que se procurar deixar vir à fala os caminhos das próprias vivências e as formas de configuração de suas expressões. Um problema que surge aqui, frente à busca de uma compreensibilidade que não é racionalização, é o do irracionalismo. A vivência religiosa não é teórica. Sua expressão também não. Uma sistemática conceitual é algo tardio no campo religioso. Mas uma compreensão filosófico-fenomenológica não tem nada a ver com racionalização. A vida religiosa é dada na e como experiência fática da vida. A tarefa aqui não é construir teorias, no sentido de modelos explicativos. A tarefa, aqui, é deixar e fazer ver os fenômenos em sua gênese historial desde a experiência da vida fática. Como contraposição ao racional ou como limite imposto ao racional, aquilo que se tem em mira, vesgamente, como o “irracional”, não vem a lume na sua originariedade e na sua constituição própria 
(HEIDEGGER, 2010). A fé e sua verdade, ateórica decerto, não aparece em seu próprio caráter de abertura, de revelação e iluminação do sagrado, do absoluto, do infinito positivo, do divino. Sua certeza não é autoasseguramento. É firmeza, consistência, estabilidade de uma insistência na verdade do mistério do divino (“mística”).

A razão, com a clareza teórica da discursividade, se inquieta e perturba com o desconhecimento. Para ela, o desconhecido não é simplesmente o não conhecido. É um elemento perturbador. O “irracional” atesta a limitação do saber teórico-objetivo. Da limitação de nosso saber objetivo nos fala uma estória de Chuang Tzu (Apud HARADA, 1972, p. 93):

\begin{abstract}
“És ou não és?”, a Luz perguntou ao Nada. O Nada era escuro e vazio. O dia todo a Luz experimentou ver. Mas não pôde ver o Nada. Auscultou. Mas não o pôde ouvir. Tentou tocá-lo. Mas não o pôde encontrar. “Oh!”, disse a Luz consigo mesmo, "isto é pois o máximo! Quem pode atingir uma tal altura?! Eu posso saber que não sei o que é o Nada. Não posso, porém, não saber que não sei o que é o Nada. Se sei que não sei o que é o Nada, resta sempre ainda o saber do meu não saber. Como pode alguém alcançar essa culminância?!”
\end{abstract}

A religião tem sua proveniência do nada do mistério. Não se trata de um nada privativo, de carência de ser e de inteligibilidade. Nem se trata de uma negatividade destrutiva ou aniquiladora ou desoladora. Não se trata nem mesmo de uma negatividade dialética, propulsora de toda a superação, na medida em que abre caminho para alguma síntese em nível superior. Trata-se, antes, de um nada transcendente. É o nada do mistério, vigente em todo o compreender como o incompreensível, em todo o falar e dizer como o silêncio e o indizível. Permanecendo no saber do seu não saber a respeito do nada, o pensamento discursivo, objetivo, experimenta e alcança o seu limite. Chega à “douta ignorância”: o saber do não-saber (Agostinho, Nicolau de Cusa). Mas há algo mais do que isso: o não saber do não saber, a "in-douta ignorância”, que a "luz”, isto é, a consciência, toma como a culminância que ela não consegue alcançar. Ela só consegue mesmo se referir ao que se dá no modo do retraimento, do não objeto, da não manifestação, atribuindo-lhe o caráter da negatividade, chamando-o de “Nada”.

O mistério, em seu a priori, não é nada de objetivo nem nada de subjetivo. É algo como horizonte de experiência. O horizonte não é nenhum objeto nem nada de objetivo. Todo objeto é que, para aparecer, precisa aparecer em determinado horizonte (de apreensão, de representação, de compreensão), numa determinada perspectiva ou enfoque. Nossa errância no leva a identificar objetividade com realidade. Como o mistério não é nada de objeto, nem nada de objetivo, temos que aludir a ele, desde esta situação, como nada. O mistério, dizíamos, é 
algo como horizonte de experiência de objetos. Não é objeto. Talvez fosse melhor dizer que o mistério é algo como um “medium”, um meio-elemento. É no éter do mistério que o homem religioso respira, vive. Talvez fosse melhor ainda dizer que o mistério é algo como uma ressonância. O homem religioso é aquele que, na experiência e como experiência, recebe a percussão do toque do mistério, e, em seu viver, deixa ser a ressonância dessa percussão. Ele estremece e vibra nesse toque (HARADA, 1972).

Nós ficamos, então, tentados a dizer. Todas estas “metáforas” do mistério, remetem à interioridade da experiência religiosa. E concebemos, então, a interioridade como algo subjetivo. O mistério seria, então, algo de subjetivo. Pertenceria à esfera da subjetividade. Entretanto, a mudança do objeto e objetivo para o sujeito e o subjetivo não muda fundamentalmente nada. A inversão de algo se mantém na mesma. Objeto e objetivo, por um lado, e sujeito e subjetivo, por outro lado, pertencem, como dois polos, a uma única e mesma relação representacional. O mistério, porém, não se dá como representação, embora tentemos, como a luz das estrelas em referência ao nada, captá-lo a partir da e através da representação; sempre em vão, porém. A interioridade da experiência do mistério não pode ser colocada na relação sujeito-objeto. A relação sujeito-objeto é algo derivado. A relação homem-mistério é originária, fundante. Não obstante, o mais habitual para nós é a relação sujeito-objeto. O lugar, em que já sempre estamos, permanece encoberto para nós:

A objetividade é o nosso modo de ser e conhecer. Nós vivemos, nós operamos nela. É ela que determina a ótica do nosso saber. Ela é o horizonte que articula, colora, orienta, cobre e domina todo o âmbito, o espaço do nosso saber. Não é possível sair desse espaço como quem livremente sai de um recinto para entrar num outro. A realidade da outra dimensão só se torna presente na negatividade. Mas não na negatividade afirmada como algo, e sim na negatividade da total e radical impossibilidade de dizer algo sobre ela (HARADA, 1972, p. 98).

Pensar o sagrado, o absoluto, o infinito, o divino desde o nada do mistério, como um além do racional e um além do mundo, significa ainda estar preso à medida do mundo e do racional. Como seria um pensamento que não encarasse o mistério como além ou como limite? Um pensamento que tivesse no mistério o seu próprio elemento? Tal pensamento encontraria no mistério sua morada. Insistir no mistério seria sua alegria, sua jovialidade. Tal pensamento seria a clareira do mistério. Seria o lugar em que o mistério se abre e se recolhe. Seria ressonância do mistério. Seu relacionamento com o mistério seria não negativo: nem negação, nem negação da negação. Pura positividade com o mistério. 


\section{No caminho da fenomenologia transcendental e da fenomenologia-hermenêutica}

A caminho de tal pensamento do mistério está, a nosso ver, a fenomenologia. A investigação fenomenológica procura tematizar (sem “teorização” ou “racionalização”) a dinâmica de significação do fenômeno em seu pertencimento ao todo da vida (ou mundo da vida). Na experiência e como experiência se dá a relação significativa do fenômeno com o humano (consciência, Dasein). Em seu ponto de partida, a fenomenologia, enquanto método de investigação filosófica, se exerce, então, como análise fenomenológica da intencionalidade. "Por esta análise prospectiva, o homem é conduzido a entrever a redução e a constituição do fenômeno, nas quais se deixam interpelar as fontes geradoras tanto da consciência, nos seus diferentes níveis, como de seus correspondentes conteúdos” (LEÃO, 2011, p. 15).

Há realidades e realizações das mais diversas estruturas. Intencionalidade é a origem ontológica quer para o objeto e sua forma de objetualidade quer para sujeito e sua forma de subjetividade que a cada vez lhe é correlato. Cada região de ser do ente se abre a partir de um projeto transcendental prévio. As ciências da religião quando investigam e teorizam já pressupõem como o incontornável de sua pesquisa a região de ser própria do fenômeno religioso. Em seus fundamentos a abertura desta região de ser já sempre está pressuposta. Se o sentido de ser do religioso não se abre, é impossível apreender templos, santuários, altares, imagens e estátuas religiosas como religiosas. No máximo, apareceriam como obras de arte. Se o sentido de ser do artístico não se abre, é impossível apreender obras de arte como obras de arte. No máximo, seriam captadas como meras coisas materiais. É certo que as obras de arte também têm um caráter “coisal”, mas elas não são meras coisas, nem coisas de uso. É certo que as imagens e estátuas religiosas podem ser também obras de arte (quando não são kitsch), mas o homem religioso enquanto tal não se relaciona com elas como obras de arte, isto é, na perspectiva artística, ou, pior ainda, estética (ROMBACH, 1988).

Na fenomenologia, a redução fenomenológica re-conduz o fenômeno, a cada vez, ao seu caráter de ser fenômeno para uma forma de consciência determinada. Fenômeno e consciência se co-pertencem mutuamente e constituem uma unidade, na dinâmica da intencionalidade.

Intencionalidade diz o caráter de ser dirigido do sujeito a um objeto e o serdirigido do objeto para um sujeito. Mas não qualquer direcionamento que o sujeito a seu bel prazer pode assumir ou de que ele pode se desligar, chamase intencionalidade, e sim só aquele que constitui a respectiva forma 
fundamental do sujeito. Contudo, ao mesmo tempo ela constitui também o caráter de ser-constituído do objeto, pois este é - se ele é captado como "fenômeno", isto é, se ele aparece como constituição fundamental para possíveis objetos contrapostos (Gegenstände) desta respectiva espécie de objeto (Objekt) - um modo respectivo de compreensibilidade do ente (ROMBACH, 1988, p. 121).

Cada região de ser aberta na e com a intencionalidade tem uma constituição de ser própria e, a cada vez, provoca em nós uma compreensão de sentido própria. Cada região de ser é uma estrutura de sentido sempre em gênese. O que nós chamamos de "realidade" é toda uma estratificação de dimensões, de regiões do ser, de estruturas de sentido. O "sagrado” é, pois, uma região de ser, um estrutura de sentido em gênese, um mundo fenomenal (diverso do mundo da arte, da filosofia, etc.).

A fenomenologia, enquanto método de investigação filosófica, se exerce, pois, ulteriormente, no fio condutor da análise intencional, como pesquisa da constituição. A investigação fenomenológica está centrada "na experiência intuitiva da verdade que se dá enquanto gênese de um determinado conteúdo constituído (noema) e do processo de relacionamento do homem transparente e transiente com qualquer conteúdo (nóesis)” (LEÃO, 2011, p. 15). Os vários estratos da “realidade” se constituem, pois, de modo noético-noemático. Na investigação da religião isso significa:

O fato religioso (enquanto humano) não contém simplesmente uma estrutura do tipo p. ex. de cristal ou mesmo de um organismo vivo. Pois ele é fato, mas não um fato físico no sentido usual, mas uma factualidade toda própria humana. O fato humano, a fortiori religioso, constitui uma estrutura digamos significativa, i. é, um conjunto de elementos certamente materiais, mas portadores de uma significação ou uma intenção humana significativa existencial. Nesse sentido, nenhum fenômeno humano religioso se esgota nos elementos que uma análise puramente empírica pode descobrir, por mais detalhada e aguda que ela seja. Assim, o fato humano religioso se inscreve num mundo específico, determinado pela intenção que o sujeito põe no jogo de relacionamento com ele ((HARADA, 2021, p. 3).

Assim, o fato religioso, enquanto polo noemático da intenção humana se oferece como um material constituído por uma e em uma forma de significação existencial. Ele não é algo simplesmente ali presente, objetivamente dado, mas ele é impregnado por uma pregnância intencional, é in-formado pela forma do ato religioso, que é o outro polo, o noético, da intenção humana. O fenômeno religioso é, pois, este todo, esta unidade noético-noemática, que acontece como a correlação intencional de ato religioso e fato religioso. Por ser impregnado por uma 
intenção humana, o fato religioso sempre traz os índices das regiões da experiência humana e dos mundos humanos em que eles vêm à luz. Deste modo, uma mesma "matéria” pode se apresentar in-formada por diferentes formas. A realidade material de um símbolo pode, assim, ser iluminada e desvelada em diferentes perspectivas de significação e de sentido. A figura do “dragão”, por exemplo, pode ter significações tão diversas, que chegam a ser antagônicas, como, por exemplo, a significação e o sentido do dragão no oriente asiático e no ocidente europeu. Por isso, uma descrição fenomenológica, que é sempre uma interpretação hermenêutica, ao mesmo tempo, precisa descobrir, a cada vez, a estrutura significativa do fato religioso através de múltiplas manifestações historiais.

Tudo isso, esse aspecto constitucional do fenômeno traz uma tarefa toda própria ao pesquisador. A de dar atenção todo específico e próprio (sic) à dimensão intencional do fato: a pura descrição deve se converter em compreensão verdadeira do fato. Aqui não basta pois a fidelidade de um espectador neutro. Não basta, de fora do fato, analisar objetivamente todos os aspectos e realizar uma visão empírica panorâmica. Exige do intérprete a capacidade de comunhão com a intenção religiosa determinante do mundo específico no qual se inscrevem todas as suas manifestações. É penetrar numa outra existência, deixando suspensa a atividade do simples espectador. Exigese aqui pulso e finura da "consonância” (Stimmung, Einfühlung, feeling). É conviver o movimento genético e estruturante dos mundos (HARADA, 2021, p. 3-4).

A busca pela estrutura estruturante do fenômeno, no caso, pelo que estrutura o fenômeno religioso, pelo que o determina de antemão, pelo que rege desde o início até o fim, pelo sua límpida vigência (vigor perdurante), enquanto doação de ser, leva a superar as factualidades dos fatos e o horizonte do empírico, do contingente, do casual, do epifenomenal. Ter a visão para a forma, isto é, para o essencial, para vigor doador de ser, é a busca da redução eidética. “A redução eidética investiga a estrutura estruturante do fenômeno, na qual todos os conteúdos podem ser reduzidos à forma essencial e mostrarem-se como concreção da verdade” (LEÃO, 2011, p. 15).

Scheler foi quem de maneira inaugural chamou a atenção para isso. A fenomenologia essencial, eidética, procura captar a estrutura estruturante, a forma doadora de vigor de ser, próprio da religiosidade, vigente nas religiões. Na fenomenologia da religião, impõe-se a tarefa de captar o eidos da religiosidade se dando nas diversas concreções dos fenômenos religiosos e das religiões. Pergunta-se pela essência do ato, da vivência, da experiência que se chama de religioso/a. Mas a essência não pode ser compreendida como mera representação genérica ou como conceito abstrato. Não deve ser entendida nem mesmo só como quididade ou definição 
(sentido lógico da essência). Muito menos deve ser concebida de modo hipostasiado, como algo “suprassensível”. O não-sensível não precisa ser “suprassensível”. Aqui, a essência precisa aparecer, antes, em sua essencialidade, isto é, como vigor doador de ser em plenitude que atua sempre em cada realização concreta.

As configurações da vivência devem sempre ser tomadas somente na essência e somente a partir de suas situações autênticas e dos círculos de situações possíveis. Trata-se da plenitude concreta, precisamente no eidos e não de conceitos genéricos isolados e abstraídos.

Problema da concrescência eidética e isso sempre junto com a construção plena para dentro das estruturas universais da vivência e as possibilidades de modificação (HEIDEGGER, 2010, p. 293).

A essência, aqui, não pode ser entendida de modo racionalista neokantiano nos moldes de uma “validez genérica universal” (HEIDEGGER, 2010, p. 308), mas como vigor perdurante doador de ser. O ente é fenômeno quando ele aparece em seu ser, isto é, em seu sentido de ser, como intencionalmente constituído. “Constituição é o conceito da intencionalidade, se isto for tomado na perspectiva de seu ser-fundante para subjetidade (Subjektität) e para objetidade (Objektität)” (ROMBACH, 1988, p. 122). A investigação fenomenológica se consuma na redução transcendental.

Redução transcendental e constituição perfazem uma unidade. O método fenomenológico, com o fio condutor da intencionalidade, com a descoberta da intuição categorial, e com a compreensão nova do a priori, abre todo um conjunto de níveis e estratos da "realidade", mostrando cada qual acontecendo em sua constituição desde a dinâmica da intencionalidade. “A redução transcendental tem a ver com a pergunta pelo processo gerador de todas as estruturações de sentido, sonda a força que ultrapassa os limites de suas estruturações e é anterior a toda a constituição de qualquer sentido do real” (LEÃO, 2011, p. 15-16).

Cada âmbito de fenômenos tem sua própria forma de consciência e sua própria forma de iluminação, de esclarecimento. Assim, a intencionalidade do ato religioso, da vivência religiosa, da experiência existencial religiosa, tem sua própria forma de consciência - a consciência "religiosa" - e a sua forma de iluminação, de esclarecimento - o "conhecimento religioso". É somente na intencionalidade que abre e funda o ato da fé que se põe, no medium do sagrado, em relacionamento com Deus enquanto Deus, isto é, com o Deus divino que se doa 
e se revela como mistério (totalmente outro ou não-outro, segundo Nicolau de Cusa), o qual, nesta experiência, pode ser recebido e acolhido como presença viva.

Fora da dimensão do ato de fé, o Deus representado pelo homem se torna um ídolo. O fenômeno divino não aparece em sua verdade, mas ele é representado como um “eídolon”, isto é, como um pequeno “eídos”, como uma ideiazinha, produzida pelo próprio espírito humano. Em referência ao divino "só o crente sabe também, em que ele pensa; aquele que meramente pensa não sabe, em que no fundo ele crê” (ROMBACH, 1973, p. 479). Ao se falar de “experiência de Deus”, o que se tem em mente com a palavra “experiência” é a imediata e constitutiva copertença de nóesis e noema no âmbito de fenômenos religiosos.

\section{Fenomenologia do sagrado como hermenêutica e hermética}

Falamos, aqui, de "Fenomenologia descritiva”. Talvez esta não seja uma expressão adequada. Toda a fenomenologia é, de certo modo, descritiva, seja ela factual ou essencialeidética, empírica ou transcendental. Trata-se, sempre, de descrever os fenômenos em suas datidades, seja no nível da captação dos fatos da experiência, seja no nível da captação das suas formas, das suas essências ou estruturas determinantes; seja no nível de uma reflexão que toma a consciência em sua factualidade, como campo de fenômenos psíquicos, seja no nível de uma reflexão que toma a consciência em sua estrutura no sentido da subjetividade transcendental. Mesmo ali onde o "lógos” do fenômeno, portanto sua fenomeno-logia, sua dinâmica de articulação de sentido, não é a consciência, mas a existência (ou o Da-sein: o círculo aberto para a irrupção do ser e dos entes enquanto tais, como em Heidegger), também está em jogo, em primeiro lugar, um exercício de descrição, não da factualidade de ocorrências, mas da facticidade da experiência da existência, em seu caráter de compreensão do ser, e, respectivamente, de exercício de responsabilização, a cada vez, por seu sentido (sua verdade manifestativa).

Entretanto, quando falamos de "fenomenologia descritiva" estamos intencionando um primeiro empenho, ainda no campo empírico, da factualidade, de descrever o fenômeno religioso, de modo científico-objetivo, nas suas mais diversas concreções e em seus devires. Ela se distinguiria de uma "fenomenologia essencial”, própria de uma "filosofia fenomenológica", que é sempre, de algum modo, uma investigação ontológica. Na primeira, a religião aparece como objeto (Gegenstand / Objekt) da pesquisa científica (história das religiões, psicologia da religião, sociologia da religião, antropologia da religião, etc.). $\mathrm{Na}$ 
segunda, a religiosidade aparece como coisa (Sache) da investigação filosófica, de sua reflexão, que tem o caráter de uma meditação, de uma movimento de ir em busca do e de seguir o sentido (Be-sinnung) do fenômeno.

A fenomenologia, enquanto meditação, é essencialmente hermenêutica. É sempre um empenho de compreensão e interpretação no medium da linguagem. Interpretação é um traço fundamental da existência humana. Na verdade, em nenhum momento o ser humano deixa de interpretar. É interpretando que ele atua todos os seus comportamentos com aquilo que ele é ou com aquilo que ele não é. Não é assim que, primeiro há o ser humano, e depois vem o interpretar, como um ato incidental ou eventual. Não, ser um ser humano é interpretar (LEÃO, 2008). Assim, em toda a descrição do fenômeno religioso em seu caráter de sacralidade sempre está em jogo também um empenho de interpretação, que se manifesta já na tentativa de captação da significação, respectivamente, da articulação de sentido (do “lógos”) do fenômeno. O "lógos” do fenômeno e, respectivamente, da fenomenologia (do discurso fenomenológico), pois, tem o caráter de um “hermeneuein”, isto é, da exposição da mensagem, isto é, do que se anuncia, do que se dá a ver e conhecer, a compreender. Neste sentido, fenomenologia e hermenêutica são um. Isso vale também para o campo do estudo da religião: uma fenomenologia da religião requer sempre uma hermenêutica da religião. Nós estamos sempre interpretando. A questão é se e em que sentido e em que medida nossa interpretação consegue se tornar hermenêutica. Uma interpretação que pretende esclarecer o fenômeno em seu "lógos" (sua articulação de sentido imanente) operando com uma recondução do desconhecido ao conhecido, do incompreensível ao compreensível, não é radical o bastante para ser hermenêutica.

Ao interpretar tematicamente algo em questão, operamos sempre com uma determinada interpretação de interpretação. Contudo, quase nunca buscamos a essência, a raiz (radix) do que é interpretar, isto é, da interpretação hermenêutica. Mas, o que é interpretar? Escutemos a linguagem de nossas línguas neolatinas. Para elas, interpretação é inter-mediação. Interpretar é prestar o serviço de mediador (inter-pretari). “Assim, inter-pretar diz intermediar, fazer mediação entre pessoas e coisas, entre situações e criações” (LEÃO, 2017, p. 18). Mas tal mediação se dá no "medium” da linguagem (GADAMER, 1997). A interpretação radical, hermenêutica, não fica só no "medium" da linguagem enquanto "medium” do discurso (do pensamento discursivo). Ela se finca no "medium" da linguagem enquanto se deixa reconduzir ao "medium-silentium”, para usar uma expressão de Mestre Eckhart, comentada por Harada 
(2006). “É que o mistério de toda criação histórica ribomba sempre no silêncio da Linguagem” (LEÃO, 2017, p. 18). Linguagem, aqui, não está sendo tomada como o falar humano e seu dizer. Linguagem diz o vir à luz do lógos, da fenomeno-logia dos fenômenos. Por e para se fazer hermenêutica, a interpretação precisa ser fenomenológica, isto é, ela precisa seguir e servir à fenomeno-logia dos fenômenos. “Todo e qualquer fenômeno já é em si mesmo, como fenômeno, fenomenologia. No aparecimento e no desaparecimento de sua vigência passa a recolher o ser e acolher o nada de suas diferenças e referências a si mesmo e a todos os demais fenômenos” (LEÃO, 2013, p. 27). A interpretação se faz hermenêutica quando consegue ser deixar-se interpelar pelo e corresponder ao apelo do silêncio da Linguagem, do Lógos dos fenômenos. O Lógos, a Linguagem originária, não é a fala humana. É a saga do dizer do mundo:

Coisa, toda e qualquer, sempre, ao ser ou aparecer como tal, é ou aparece como determinação, melhor, como concretização e diferenciação ou alteração de sentido (lógos, mundo) sempre já posto ou interposto. E é isso, a saber, o expor-se do sentido, que é o fazer-se ou concretizar-se (realizar-se) da própria linguagem, que sempre aparece ou se concretiza (realiza) como isso ou como aquilo (diferenciando-se, singularizando-se), ao ser chamado (o sentido), ao ser evocado à palavra - quer dizer, falando, nomeando. Este ser chamado à palavra, este falar e nomear é cumprimento da necessidade de sentido (lógos, mundo), que é aparecer, mostrar-se, fazer-se visível. Assim é vida (FOGEL, 2017, p. 37-38).

A Linguagem, isto é, o lógos (a força de reunião) que vige e rege toda a fenomeno-logia dos fenômenos, na dinâmica de aparecimento e desaparecimento, de presença e ausência, de diferenciação e individuação e de copertença a uma identidade comum e de universalização, é o que pre-jaz e sub-jaz a todo o interpretar humano. A interpretação se faz hermenêutica quando consegue, de modo mais ou menos feliz, nomear, isto é, evocar, deixar vir à proximidade e mostrar, revelar, tornar visível, este lógos sub-jacente, pre-jacente (mundo). Interpretar é, em sentido radical, dar atenção a este deixar-subjazer do lógos e, pela palavra que nomeia, trazê-lo à proximidade, tornando-o visível no modo como, em cada coisa, em cada fenômeno, ele está acontecendo. Assim, cada fenômeno é singular e, ao mesmo tempo, universal. Dar atenção à dinâmica de sentido do Todo, dando-se em cada singular, é o desafio da interpretação originária, fenomeno-lógica.

A fenomenologia busca compreender a dinâmica de sentido do Todo, como um Todo no seu momento cada vez singular. Assim, a intenção fundamental da fenomenologia está focada em captar a dinâmica de significação que o fenômeno consegue mostrar de si mesmo nesta pertença cada vez singular ao todo da Vida. Por isto, o foco de toda a evidência da fenomenologia é, em 
última instância, a experiência, a relação significativa do fenômeno com o homem (LEÃO, 2011, p. 15).

Uma interpretação é tanto mais hermenêutica quanto mais fenomenológica. E viceversa: é tanto mais fenomenológica quanto mais hermenêutica. A interpretação se torna, assim, vazio de uma abertura, disponibilidade para uma acolhida, espera e escuta do advento inesperado e silencioso do Lógos. Cada advento traz consigo um apelo de transformação do homem. Um interpretação fenomenólogico-hermenêutica não acontece sem que o intérprete, na experiência do interpretar, se transforme, vindo a ser mais propriamente o que ele é (enquanto ser humano). Compreender é projetar novas possibilidades de ser. O que mais obsta a compreensão e a interpretação não é a não-verdade no sentido da mentira, do engano e do erro, bem como da inautenticidade. É a pretensão de possui a verdade como um luz sem sombras, é o deslumbramento do óbvio, do familiar, é o convencimento do conhecido, que passa por inquestionável. Uma interpretação do pensamento, fenomenológica-hermenêutica, caminha no entremeio entre a verdade do que se mostra e a não verdade originária, o não mostrar-se do mistério. Por isso, uma interpretação fenomenológico-hermenêutica se dá na acolhida da compreensão e da incompreensão (como experiência da não verdade, isto é, do não desvelamento, do mistério).

Nenhuma interpretação teme incompreensão, a incompreensão de sua Verdade e Não Verdade. Pois pertence a toda criação sentir a Linguagem nas falas das línguas. Aqui interpretar não é levar o que é obscuro e não sabido para o âmbito claro e distinto da razão e do conhecimento. Interpretar consiste em deixar-se conduzir pelo silêncio das muitas falas para o desconhecido do mistério (LEÃO, 2017, p. 19).

Uma compreensão da hermenêutica como arte ou técnica de interpretar, que toma o interpretar como um explicar, e o explicar como um esclarecer, no sentido de um trazer o desconhecido para o conhecido, o estranho e inusitado para o familiar e óbvio, o paradoxal para a opinião corrente, é insuficiente. Isto vale sobretudo quando estão em jogo os fenômenos da criação histórica humana: da arte, da religião, da filosofia. Uma interpretação se torna hermenêutica quando deixa reconduzir as muitas falas verbais e não verbais da criação humana, ao silêncio e ao desconhecido do mistério de ser. A hermenêutica se faz, assim, hermética.

Tanto em "hermenêutica” quanto em "hermética” ouvimos uma ressonância do nome do deus grego “Hermes”. Hermes evoca a experiência do extra-ordinário do mistério dando-se no ordinário da vida. O advento do extra-ordinário do mistério se dá de modo súbito, no instante inaugural de toda a criação humana. Traz a marca do ab-soluto, isto é, daquilo que, solto de 
tudo, livre, não se refere a nada fora de si. É o dar-se da experiência da transcendência e da transcendência da experiência:

\begin{abstract}
Imediatamente, subitamente dá-se, faz-se, é, há. Este modo de ser, a imediatidade ou subitaneidade, marca ou define transcendência. Transcendência é a circunscrição ou o âmbito subitamente aberto, instaurado, e que é o lugar, a hora - é isso o âmbito - do homem, i. é, da vida, da existência. O salto nele mesmo já é transcendência. E é transcendência à medida que é pura gratuidade, puro acontecimento, ou seja, pura doação. É graça e de graça. Porque de graça, graça. Dá-se, faz-se, acontece e sempre já se deu, sempre já se fez, sempre já aconteceu, desde nada, por nada, para nada. O divino, o sagrado, o extraordinário é não ser, não ter, não precisar ser ou ter nenhum começo, nenhum princípio, nenhuma causa: gratuidade, abyssalidade - pura transcendência.
\end{abstract}

Cheio deste acontecimento, completamente tocado e atravessado por este modo de ser, a saber, transcendência, o poeta exclama e, então, abre e pontua toda a poética de Sonetos a Orfeu:

"Uma árvore irrompeu. Ó pura irrupção! Ó pura emergência! Ó pura transcendência! (FOGEL, 2017, p. 25-26).

O nome de Hermes evoca, no pensamento mítico grego, o extraordinário desta pura transcendência, dando-se como irrupção súbita, inesperada, de uma iluminação, de uma revelação, de um anúncio, da doação de uma mensagem advinda do mistério. Hermes é o “deus vindouro", o deus que vem, melhor, o divino que vigora e se dá como vinda, como advento (ROMBACH, 1991). É o deus adveniente na medida em que é o deus do advir. É o deus do instante. O instante é a pura emergência, desde nada e para nada, que recolhe tudo, passado e futuro e atualidade, na subitaneidade e imediatidade de uma iluminação. Hermes é o deus escondido. É o deus do escondido. É o oposto do seu meio-irmão, Apolo, deus do desvelamento, do desescondimento. Toda a criação humana, na arte, na religião, na filosofia, está na tensão dos opostos de Apolo e Hermes, de desescondimento (do compreensível) e escondimento (do incompreensível). Apolínea é a dimensão da fundação e do fundamento (dos princípios e das causas). É a dimensão da explicação e da compreensão. Hermética é a dimensão do abismo (retraimento do que recusa fundamento, princípio, causa). Apolínea é a dimensão de superfície da vida, onde se movem ciência, técnica, saber e poder. Hermética é a dimensão da profundidade, isto é, do que, na superfície, se retrai. Nessa dimensão se radicam as obras da criação humana na arte, na religião, na filosofia. Apolínea é a dimensão do dizível. Hermética, a dimensão do indizível. Religião é fenômeno hermético. Fenomenologia da religião, para ser o que ela é, carece de fazer-se hermenêutica-hermética. Não podemos aqui, em razão da 
brevidade deste artigo, desenvolver este tema. Contentamo-nos a remeter à obra de Heinrich

Rombach “O Deus vindouro” (1991).

\section{REFERÊNCIAS}

ARISTOTELE. Etica Nicomachea. Milano : Rusconi, 1998.

DILTHEY, W. Ideias acerca de uma psicologia descritiva e analítica. Covilhã: LusoSofia, 2008.

DURKHEIM, É. Les formes élémentaires de la vie religieuse. Paris: PUF, 2013.

ELIADE, M. Traité d'histoire des religions. Paris: Payot, 1949.

FOGEL, G. O desaprendizado do símbolo: da experiência da linguagem. Rio de Janeiro: Mauad X, 2017.

FREUD, S. The Future of an Illusion - The Standard Edition of the Complete Psychological Works of Sigmund Freud Vol. XXI. London / New York: Hogart / Liveright, 1961.

GADAMER, H-G. Verdade e Método I: Traços fundamentais de uma hermenêutica filosófica. Bragança Paulista / Petrópolis: EDUSF / Vozes, 1997.

HARADA, H. Reflexões de quem não sabe o que é oração. In: Boff, L.; Spindeldreier, A. e

HARADA, H. Coisas, velhas e novas: à margem da espiritualidade franciscana. Bragança Paulista: EDUSF, 2006.

HARADA, H. Fenomenologia da religião. Curitiba, 2013, Disponível em: freiharada.com.br. Fonte: $\mathrm{O}$ legado do Hei Hógenes Harada: https://pt.scribd.com/document/185465968/Fenomenologia-da-Religiao. Acesso em: 28 de Fevereiro de 2021.

HEIDEGGER, M. Fenomenologia da vida religiosa. Bragança Paulista / Petrópolis: EDUSF / Vozes, 2010.

HEIDEGGER, Martin. Ser e Tempo. Petrópolis / Bragança Paulista: Vozes / Edusf., 2012.

HUSSERL, E. Phänomenologische Psychologie (Husserliana IX). Den Haag: Nijhoff, 1968.

HUSSERL, E. Logische Untersuchungen II/2: Elemente einer phänomenologischen Aufklärung der Erkenntnis. Tübingen: Max Niemeyer, 1993a.

HUSSERL, E. Ideen zu einer reinen Phänomenologie und phänomenologischen Philosophie. Tübingen: Max Niemeyer, 1993b.

JAMES, W. As variedades da experiência religiosa: um estudo sobre a natureza humana. São Paulo: Cultrix, 2017.

JUNG, C. G. Espiritualidade e Transcendência (seleção e edição de Brigitte Dorst). Petrópolis: Vozes, 2015. 
LEÃO, E. C. Aprendendo a Pensar I: o pensamento na modernidade e na religião. Teresópolis: Daimon, 2008.

LEÃO, E. C. Filosofia grega: uma introdução. Teresópolis: Daimon, 2010.

LEÃO, E. C. Apresentação. FERNANDES, M. A. À clareira do ser: da fenomenologia da existência à abertura da existência. Teresópolis: Daimon, 2011, pp. 15-16, 2011.

LEÃO, E. C. Filosofia Contemporânea. Teresópolis: Daimon, 2013.

LEÃO, E. C. Aprendendo a pensar III. Teresópolis: Daimon, 2017.

MÜLLER, M. The Science of Language. London: The Project Gutenberg Ebook, 2010.

OTTO, R. Kantisch-Frieschische Religionsphilosophie. Marburg: Universität Marburg, 1909.

OTTO, R. O sagrado. Lisboa: Edições 70, 2005.

RIES, J. L'uomo e il sacro: tratatto di antropologia religiosa. In: RIES, J et alii. Le origini e il problema dell'uomo religiosus. Milano: Jaca Book, 1989, pp. 23-31.

ROMBACH, H. Die Religionsphänomenologie. Ansatz und Wirkung von M. Scheler bis H. Kessler. In Theologie und Philosophie. Freiburg / Basel / Wien: 73, 4, p. 477-493, 1973.

ROMBACH, H. Der kommende Gott. Hermetik - eine neue Weltsicht. Freiburg im Breisgau: Rombach Verlag, 1991.

ROMBACH, H. Die Gegenwart der Philosophie: die Grundprobleme der abendländischen Philosophie und der gegenwärtige Stand des philosophischen Fragens. Freiburg / München: Karl Alber, ${ }^{3} 1988$.

SCHELER, M. Le Saint, le génie, le héros. Fribourg en Suisse: Egloff, 1944.

SCHELER, M. L'eterno nell'uomo . Roma: Edizioni Logos, 1991.

SÖDERBLOM, N. Ausgewählte Werke. Band I: Offenbarung und Religionen. Göttingen: Vandenhoeck und Ruprecht, 2011.

TROELTSCH, E. Psychologie und Erkenntnistheorie in der Religionswissenschaft. Eine Untersuchung über die Bedeutung der Kantischen Religionslehre für die heutige Religionswissenschaft. Tübingen: Scholar Select, 1915.

VAN DER LEEUW, G. Phänomenologie der Religion. Tübingen: Mohr, 1933.

WINDELBAND, W. Präludien II. Tübingen: Mohr, 1915. 